\title{
Does the Type of Resuscitative Fluid Affect Healing of Colonic Anastomosis in Experimentally Induced Hemorrhagic Shock in Rats?
}

\author{
Ali Harlak ${ }^{a}$ Mehmet Fatih Can ${ }^{a}$ Oner Mentes ${ }^{a} \quad$ Nail Ersoz $^{a} \quad$ Bulent Kurt $^{b}$ \\ Turker Turker ${ }^{c}$ Gokhan Yagcia ${ }^{\mathrm{a}}$ Turgut Tufan $^{\mathrm{a}}$

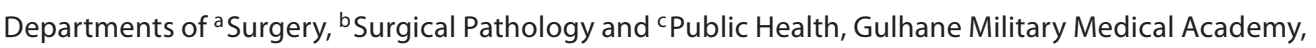 \\ Ankara, Turkey
}

\author{
Key Words \\ Hemorrhagic shock · Fluid resuscitation · Colonic \\ anastomosis - Lactated Ringer's solution - Hydroxyethyl \\ starch $\cdot$ Hypertonic saline
}

\begin{abstract}
Objective: The aim of the study was to investigate the effects of different resuscitative fluids on the healing of intestinal anastomosis in a hemorrhagic-shock rat model. Materials and Methods: Closed-colony Wistar male rats $(n=40 ; 8$ rats per group) were subjected to volume-controlled hemorrhagic shock, followed by a 30-min shock phase. The animals were then resuscitated with one of the following fluids (which also corresponds to their respective groups): lactated Ringer's solution (LR), hydroxyethyl starch (HES), 7.5\% hypertonic saline (HS) and autologous blood (AB). There was also a control group $(\mathrm{CL})$, which did not experience hemorrhagic shock or receive any resuscitative fluids. All rats underwent laparotomy, segmental resection and anastomosis of the left colon. Five days later, a 2nd laparotomy was performed and the anastomotic bursting pressure was measured in vivo. Thereafter, the anastomosed segment was resected to measure the tissue hydroxyproline level and the grade of anastomotic fibrosis. Results: All experimental groups (LR, HES, $H S$ and $A B$ ) exhibited lower anastomotic bursting pressures than the $\mathrm{CL}$ group; however, nointergroup differences
\end{abstract}

achieved statistical significance. The mean tissue hydroxyproline level and fibrosis grade also were similar across all 5 groups. Conclusion: In traumatic hemorrhagic shock, anastomosis safety does not appear to be affected by the type of fluid used for resuscitation. Moreover, LR, HES and HS all seemed to reinforce healing as effectively as transfused blood.

Copyright $\odot 2009$ S. Karger AG, Basel

\section{Introduction}

Trauma is one of the biggest causes of death worldwide, abruptly ending the lives of 5 million people each year. Among people between the ages of 5 and 44 years, 6 of the 10 leading causes of mortality are injury-related [1]. In severely injured patients who receive life-saving emergency care, injury-related problems continue to be the major source of mortality throughout the in-hospital period. Two of the main causes of death in hospitalized, injured patients are multiple organ injury and hemorrhagic shock. Especially in patients who have suffered penetrating abdominal trauma, multiple organ injury (including hollow viscus damage) may occur together with hemorrhagic shock, a combination that is particularly lethal.

\section{KARGER}

Fax +4161306 1234

E-Mail karger@karger.ch

www.karger.com
(C) 2009 S. Karger AG, Basel

1011-7571/09/0184-0255\$26.00/0

Accessible online at:

www.karger.com/mpp
Ali Harlak

GATA Genel Cerrahi AD

TR-06018 Etlik, Ankara (Turkey)

Tel. +90 312304 5020, Fax +90 3123045000

E-Mail aharlak@yahoo.com 
The presence of shock upon admission has been shown to correspond with an increased risk of mortality in patients with a penetrating injury to the colon [2]. Even with blunt trauma to the colon, mortality risk has been shown to increase significantly when there is an accompanying and potentially hemorrhagic injury to another organ [3]. In addition, for patients with penetrating and severe colon injuries, the requirement for an intraoperative transfusion of blood greater than 6 units has been shown to dramatically increase the risk of suture line breakdown and leakage after resection and anastomoses without proximal diversions [4]. In fact, primary repair has become the treatment of choice over the last decade for penetrating colon injuries without any tissue loss. There has also been a growing trend towards constructing an anastomosis after resection of the damaged colon in extensive colon injuries instead of creating a temporary colostomy. Current standards of care dictate that anastomosis safety, a key determinant of patient course, is of the highest priority for surgeons.

Currently, despite improved understanding of key mechanisms and encouraging drugs and resuscitative fluids, it is not possible to fully reverse the microcirculatory dysfunction that results from critical blood loss. It has been proven that severe hypoperfusion of end-organ vasculature leads to insufficient oxygen delivery to vital tissues and a decrease in the capacity to clear toxic cellular waste [5]. To eliminate the impact of severe, prolonged hypoperfusion, proper fluid resuscitation is mandatory.

Although the restorative value of volume replacement fluids in hemorrhagic shock has been investigated in numerous studies, the contribution of these fluids to the healing of wounded tissue remains undetermined. The present study was conducted to examine the effect of commonly used resuscitative fluids on colonic anastomosis healing in a hemorrhagic shock model using experimental rats.

\section{Materials and Methods}

Animals and General Preparation

Forty male Wistar albino rats weighing 170-250 g were used for the study. The study protocol was approved by the Animal Care and Research Committee at Gulhane Military Medical Academy. The rats were obtained from the laboratory of the Animal Research Center. During the study period, all animals were handled in accordance with the National Institutes of Health Guide for the Care and Use of Laboratory Animals. All the rats were maintained in a room at $24^{\circ} \mathrm{C}$ on a 14 -hour light/10-hour dark cycle and allowed to receive standard rat chow and water ad libitum until $12 \mathrm{~h}$ prior to surgery, when food, but not water, was withdrawn.
Experimental Protocol, Induction of Hemorrhagic Shock and Resuscitation Process

Each animal was assigned to one of 5 groups (8 rats per group), named after the resuscitative fluid administered to the group: lactated Ringer's solution (LR), hydroxyethyl starch (HES), 7.5\% hypertonic saline solution (HS), autologous blood (AB) and the control group (CL). Each animal in the experimental groups underwent colonic resection and end-to-end anastomosis after experiencing hemorrhagic shock, and subsequently received one of four different resuscitative fluids, based on group assignment. Rats in the LR, HES, HS and AB groups were intravenously administered either LR (a volume 2-fold greater than blood loss), HES (a volume equal to blood loss), HS (4 ml/ $\mathrm{kg}$ body weight) or $\mathrm{AB}$ (the entire volume of shed blood replaced), according to which group they were in. The volume of resuscitative fluid was administered at the lower limit of its usual dose. The CL underwent the same surgical procedure without experiencing hemorrhagic shock or receiving any resuscitative fluids.

Prior to surgery, animals were anesthetized with a mixed solution of ketamine/xylazine injected intramuscularly at a dose of $40 / 8 \mathrm{mg} / \mathrm{kg}$. The subsequent steps were performed after each animal was placed on a thermal pad, in order to maintain a constant body temperature of $37^{\circ} \mathrm{C}$ in the animal throughout the rest of the procedure. A rectal thermometer was used to monitor temperature. After tail-vein cannulation, bleeding was initiated and $35 \%$ of the rat's total blood volume was gradually withdrawn over $30 \mathrm{~min}$, in accordance with previously described volume-adjusted hemorrhagic shock models $[6,7]$. This model was used based on an estimate that $7 \%$ body weight would best approximate the total circulating blood volume $[6,8]$. Blood obtained from the rats in the $\mathrm{AB}$ group was collected into syringes containing $0.1 \mathrm{ml}$ of $3.2 \%$ sodium citrate/ $\mathrm{ml}$ to prevent clotting. The animals were exposed to hypovolemic shock for a further $30 \mathrm{~min}$ prior to fluid resuscitation. Thereafter, each animal received a single volume infusion of their assigned fluid within $15 \mathrm{~min}$. The venous line was removed after resuscitation.

\section{Surgical Procedure}

Rats were prepared for surgery in the supine position by shaving their abdomen. Following a povidone-iodine application, a $4-\mathrm{cm}$ midline incision was made to allow access to the abdominal cavity. The descending colon was identified and a suitable part of the colon was selected for segmental resection and immediate anastomosis. Any existing colonic content was milked down gently to the upper rectum. A $1-\mathrm{cm}$ segment of the colon was resected by dividing the gut at 2 points near to the preserved mesenteric marginal vessels. When it was not possible to preserve all vessels, the sacrificed vessel was ligated and divided close to the gut wall, and the colonic resection was carried out close to the adjacent vessels at 2 sites. A conventional end-to-end anastomosis was performed using 8 interrupted inverting sutures with 5-0 polypropylene material. In order to avoid peritoneal drying, isotonic saline was dropped onto the abdominal cavity at 1-min intervals. The incision was closed with a double layer of running 4-0 silk suture. During the postoperative period, each animal recovered in a specially assigned chamber with a single room and was given standard rodent chow and water ad libitum. The animals were visited daily until the day of the repeat laparotomy. 
Table 1. Summary of the study results

\begin{tabular}{|c|c|c|c|}
\hline Healing parameters & Study group & Results & $\mathrm{p}$ value \\
\hline $\begin{array}{l}\text { Bursting pressure } \\
\text { mm Hg }\end{array}$ & $\begin{array}{l}\text { CL } \\
\text { LR } \\
\text { HES } \\
\text { HS } \\
\text { AB }\end{array}$ & $\begin{array}{c}122 \pm 5.9 \\
78 \pm 13.3 \\
95 \pm 8.3 \\
115 \pm 5.1 \\
102 \pm 7.9\end{array}$ & NS \\
\hline $\begin{array}{l}\text { Hydroxyproline level }{ }^{2} \\
\mu \mathrm{g} / \mathrm{g}\end{array}$ & $\begin{array}{l}\text { CL } \\
\text { LR } \\
\text { HES } \\
\text { HS } \\
\text { AB }\end{array}$ & $\begin{array}{l}0.090 \pm 0.013 \\
0.083 \pm 0.011 \\
0.083 \pm 0.013 \\
0.082 \pm 0.008 \\
0.082 \pm 0.006\end{array}$ & NS \\
\hline $\begin{array}{l}\text { Degree of fibrosis }{ }^{3} \\
\text { (subgroup animal count) }\end{array}$ & $\begin{array}{l}\text { CL } \\
\text { LR } \\
\text { HES } \\
\text { HS } \\
\text { AB }\end{array}$ & $\begin{array}{l}1 / 3 / 4 \\
3 / 4 / 1 \\
4 / 2 / 2 \\
2 / 3 / 3 \\
3 / 3 / 2\end{array}$ & NS \\
\hline
\end{tabular}

\footnotetext{
${ }^{1}$ Bonferoni-adjusted Mann-Whitney U test. Intergroups comparison (all groups compared with each other, $\mathrm{p}=\mathrm{NS}$ ).

${ }^{2}$ Kruskal-Wallis test.

${ }^{3} \chi^{2}$ test; the degree of fibrosis for each group is given as the number of rats graded 1, 2 and 3, respectively.
}

Measurement of Tissue Hydroxyproline Levels

Measurement of the hydroxyproline concentration was determined in each tissue specimen. Briefly, the tissue specimen was homogenized to a fine solution in cold saline, hydrolyzed in alkali and oxidized with chloramine T. The chromophore was developed with the addition of Ehrlich's aldehyde and the absorbance of the chromophore was measured at $550 \mathrm{~nm}$. The concentration of hydroxyproline in each tissue specimen was deduced from a standard calibration curve.

\section{Assessment of Anastomotic Fibrosis}

Samples of peri-anastomotic tissue were kept in 10\% buffered formalin for at least $24 \mathrm{~h}$. After routine pathological processing, a series of sections ( $5 \mu \mathrm{m}$ thick) were cut from the paraffin-embedded blocks and stained with hematoxylin and eosin. The sections were examined under a conventional light microscope by a pathologist who was blinded to the study group. The degree of fibrosis was assessed using a scale previously described by Hooker et al. [9]. This grading scale allocates ordinal scores for fibrosis, assigning higher scores as the degree of reaction increases (0: no fibrosis, 1: minimal or loose, 2: moderate, 3: florid or dense).

\section{Data and Statistical Analysis}

Group mean values for anastomotic bursting pressure and tissue hydroxyproline levels were calculated. All results, except for fibrosis, were expressed as the mean \pm standard error of the mean and as the median \pm range. The degree of fibrosis was reported as the number of rats rated with each histological grade. To detect intergroup differences, a Kruskal-Wallis analysis of variance was performed. Significant differences were further examined by Bonferroni-adjusted Mann-Whitney $U$ and $\chi^{2}$ tests to compare the groups. In these tests, $\mathrm{p}<0.05$ was considered statistically significant. All statistical analyses were conducted using SPSS for Windows, Version 10.0 (SPSS Inc., Chicago, Ill., USA).

\section{Repeat Laparotomy, Measurement of Bursting Pressure and} Tissue Sampling

On postoperative day 5 , all rats were anesthetized with the same dosage of ketamine/xylazine mixture. A second laparotomy was carried out, at which time the anastomosis site was identified and gently isolated away from all surrounding structures. Particular attention was paid to keeping peri-anastomotic adhesions in their natural place. To measure bursting pressure in vivo, a plastic catheter was inserted into the colonic lumen at a point $4 \mathrm{~cm}$ proximal to the anastomosis. The colon was obliterated with a $4-0$ silk ligature $3 \mathrm{~cm}$ proximal and $3 \mathrm{~cm}$ distal to the anastomosis line. An infusion pump system (Life Care 5000 Infusion sSystem; Abbott Lab., Abbott Park, Ill., USA) hooked up to a pressure sensor was connected to the intraluminally placed catheter. Water, colored with methylene blue, was infused at a rate of $3 \mathrm{ml} / \mathrm{min}$. Bursting pressure was recorded as the pressure at which abrupt rupture occurred along the suture line during progressive distension of the closed-loop colonic segment. Thereafter, the colon was isolated from the mesentery, and a bowel segment, which included the anastomosis and the adjacent $2 \mathrm{~cm}$ of colon at both ends, was resected for tissue sampling. The harvested segment of colon was cut longitudinally and washed with saline. Then, one of the segments was immersed in formalin to allow for histological fibrosis grading. The remaining segment of the excised colon was kept for an evaluation of the tissue hydroxyproline level. Following this resection process, the animals were euthanized by cardiac puncture.

Effect of Resuscitative Fluid on Colonic Anastomosis

\section{Results}

\section{Adverse Events}

Five rats died of severe hemorrhagic shock: 2 (1 each in the HES and $A B$ groups) died during the period of hemorrhagic shock, 2 (1 each in the LR and AB groups) died during the resuscitative phase, and 1 (in the HS group) died at the onset of the laparotomy. Each deceased animal was replaced with another in the same assigned group. All of the rats that survived up to the postoperative recovery period had an uneventful course between the 1st and 2nd laparotomies. There were no significant intraabdominal complications, such as hemorrhage, infection, abscess or obvious breakdown at the anastomosis circle detected during repeat laparotomy.

\section{Parameters of Anastomosis Healing}

The mean bursting pressure of the anastomosis line was higher in the CL group $(122 \pm 5.9 \mathrm{~mm} \mathrm{Hg})$ than in 
any of the experimental groups. The measured mean values were as follows: $\mathrm{LR}=78 \pm 13.3 \mathrm{~mm} \mathrm{Hg}$, HES $=95 \pm$ $8.3 \mathrm{~mm} \mathrm{Hg}, \mathrm{HS}=115 \pm 5.1 \mathrm{~mm} \mathrm{Hg}$ and $\mathrm{AB}=102 \pm 7.9$ $\mathrm{mm} \mathrm{Hg}$. None of the between-group differences achieved statistical significance (table 1). Group mean tissue hydroxyproline levels were as follows: $\mathrm{CL}=0.090 \pm 0.013$, $\mathrm{LR}=0.083 \pm 0.011, \mathrm{HES}=0.083 \pm 0.013, \mathrm{HS}=0.082 \pm$ 0.01 and $\mathrm{AB}=0.082 \pm 0.01$. There were no intergroup differences in tissue hydroxyproline levels. None of the colonic segments examined were graded as grade 0 (no) anastomotic fibrosis. In the CL group, 4 out of 8 rats had grade 3 (florid or dense) anastomotic fibrosis. The numbers of rats with grade 3 in the LR, HES, HS and $A B$ groups were 1,2, 3 and 2, respectively. Three rats in the CL group, 4 in the LR group, 2 in the HES group and 3 rats in each of the HS and AB groups had grade 2 (moderate) fibrosis at their anastomosis healing line. The remaining rats in the 5 groups had grade 1 (minimal) fibrosis at the anastomosis line. No between-group differences were detected with respect to the degree of fibrosis.

\section{Discussion}

Immediate control of hemorrhage and proper fluid resuscitation remain the mainstays of the management of hypotensive patients with active bleeding. The first priorities of fluid resuscitation are to establish and maintain microcirculation that meets all the demands of critical tissues. It has been thought that a hypoxic environment in splanchnic tissues may result in a disproportionate activation of pro-inflammatory pathways which leads to systemic inflammatory response syndrome and multiple organ failure [10, 11]. Hence, ideal replacement treatment for hemorrhagic shock should be able to restore the microcirculation of intestinal tissues.

Besides the systemic events that occur indirectly, decreased blood flow to the splanchnic bed exerts a number of locally apparent detrimental effects in the gastrointestinal tract. The availability of oxygen is of paramount importance for cellular proliferation and collagen synthesis during wound healing, and it is mandatory for collagen cross-linking, which is a major determinant of the tensile strength of a wound $[12,13]$. In the present study, we investigated 4 different resuscitative fluids for preventing microcirculatory disturbances during the initial phase of physiological tissue repair.

LR and blood are frequently used in daily practice while the use of HES and HS has been increasing in recent years. When given in large volumes, LR's plasma-expand- ing capacity is limited, but it does rapidly increase the mean arterial pressure to near pre-hemorrhage levels [1416]. Generally, resuscitation with crystalloids during hemorrhagic shock has been shown to result in shortlasting restoration of mean arterial pressure levels, poor dilatation of mesenteric arteriolar vessels and relative failure at increasing microvascular blood flow to the intestine [15]. Moreover, the traditional practice of injudiciously infusing crystalloids into the hypotensive trauma patient has been well-recognized to lead to dilutional coagulopathy and impaired blood viscosity, both of which can eventually exacerbate pre-existing bleeding [5]. Our study did not reveal any clear superiority of LR over the other solutions at improving anastomosis safety. However, the animals in the LR group did not have any anastomosis-related complications in the abdomen, and exhibited a level of anastomosis healing similar to those resuscitated with other fluids based on the histological, biochemical and physical outcomes.

Our results confirmed some previous reports about HES [14], but not others which showed a transient, moderate restoration of mesenteric microvascular blood flow that failed to maintain pre-shock levels of microvascular blood flow after $60 \mathrm{~min}$ of resuscitation [15]. Microvascular oxygen tension and tissue $\mathrm{pH}$, measured $90 \mathrm{~min}$ after resuscitation with HES, dropped to levels which were inadequate to meet tissue demands [6]. The observed differences could be due to the methodologies used in the study.

Infusion of HS in small volumes has been shown to redistribute interstitial fluid into the intravascular space [17], improve heart contractility, as well as mesenteric oxygen delivery and consumption [18], and act as a relaxant for vascular smooth muscle [19]. Although some have concluded that combinations of hypertonic and hyperoncotic solutions (e.g. 10\% dextran or HES + 7.2\% HS) are the most efficacious at improving tissue perfusion of intestinal organs during hemorrhagic hypotension [20], we preferred using these solutions separately to determine their independent effects on wound healing. Our results showed that the resuscitative fluids had a similar effect on wound healing after hemorrhagic hypoperfusion consistent with previous reports [21,22].

The results of the present study also showed that whole blood transfusion, after protracted hemorrhagic shock, provided wound healing comparable with that observed in normovolemic rats, but not consistent with reports of Buchmiller-Crair et al. [23] and Tadros et al. [24]. These investigators claimed that blood transfusions were associated with a significant reduction in the breakage 
strength of colonic anastomoses. However, the adverse effects of blood transfusion on wound healing are likely to be related to its immunosuppressive features, which, in turn, are surmised to interfere with cell-mediated mechanisms.

The lack of a nonresuscitated hemorrhage control group was one of the limitations of our study. However, it is probably impossible to achieve prolonged survival (5 days) in nonresuscitated animals that have lost 35\% of their total circulatory volume, as demonstrated in prior studies [7,23]. In fact, controls have been absent from a considerable proportion of the published studies on longstanding effects of hemorrhagic shock. Small sample size was another limitation of our study, as we included only 8 animals in each group and we might have lacked the statistical power to detect clinically meaningful intergroup differences. We selected 8 rats per group based on previously published papers $[7,15]$.

Our study also could have been strengthened by examining the molecular mechanisms of wound healing. A number of experimental measures have previously been used to determine the quality of wound healing. However, the measurement of anastomotic bursting pressure remains the most commonly practiced method of evalu- ating anastomosis safety $[25,26]$. In addition, the tissue hydroxyproline level and grade/density of fibrosis at the anastomosis site are known to be two reliable predictors of anastomosis healing [26, 27]. Consequently, we feel confident that we selected parameters that would allow us to accurately determine the level of anastomosis healing.

The dosage regimen adopted for the administration of fluids may also raise some concern. Since the adverse effects of over-resuscitation (e.g. precipitating rebleeding) were recognized by trauma researchers, considerable interest has been directed toward small-volume resuscitation (permissive hypotension), which has proved to have some positive impacts on the survival of trauma victims [5]. For this reason, we preferred to administer each type of fluid at the lower limit of its usual dosage.

\section{Conclusion}

Our results showed that, alone, the infusion of RL or HES produced intestinal healing comparable to that achieved using $\mathrm{HS}$ or $\mathrm{AB}$ in experimental hemorrhagic shock.

\section{References}

1 World Health Organization: How can injuries be prevented? 2006.http://www.who.int/ features/qa/36/en/index.html.

$\checkmark 2$ Adesanya AA, Ekanem EE: A ten-year study of penetrating injuries of the colon. Dis Colon Rectum 2004;47:2169-2177.

3 Ricciardi R, Paterson CA, Islam S, Sweeney WB, Baker SP, Counihan TC: Independent predictors of morbidity and mortality in blunt colon trauma. Am Surg 2004;70:7579.

-4 Miller PR, Fabian TC, Croce MA, Magnotti LJ, Elizabeth Pritchard F, Minard G, Stewart RM: Improving outcomes following penetrating colon wounds: application of a clinical pathway. Ann Surg 2002;235:775-781.

5 Revell M, Greaves I, Porter K: Endpoints for fluid resuscitation in hemorrhagic shock. J Trauma 2003;54(suppl 5):63-67.

6 Cabrales P, Nacharaju P, Manjula BN, Tsai AG, Acharya SA, Intaglietta M: Early difference in tissue $\mathrm{pH}$ and microvascular hemodynamics in hemorrhagic shock resuscitation using polyethylene glycol-albumin-and hydroxyethyl starch-based plasma expanders. Shock 2005;24:66-73.
7 Lee CC, Chang IJ, Yen ZS, Hsu CY, Chen SY, Su CP, Chiang WC, Chen SC, Chen WJ: Effect of different resuscitation fluids on cytokine response in a rat model of hemorrhagic shock. Shock 2005;24:177-181.

8 Cabrales P, Tsai AG, Intaglietta M: Hyperosmotic-hyperoncotic versus hyperosmotichyperviscous: small volume resuscitation in hemorrhagic shock. Shock 2004;22:431437.

9 Hooker GD, Taylor BM, Driman DK: Prevention of adhesion formation with use of sodium hyaluronate-based bioresorbable membrane in a rat model of ventral hernia repair with polypropylene mesh - a randomized, controlled study. Surgery 1999;125: 211-216.

10 Adams JM, Hauser CJ, Adams CA Jr, Xu DZ, Livingston DH, Deitch EA: Entry of gut lymph into the circulation primes rat neutrophil respiratory burst in hemorrhagic shock. Crit Care Med 2001;29:2194-2198.

-11 Deitch EA, Xu D, Franko L, Ayala A, Chaudry $\mathrm{IH}$ : Evidence favoring the role of the gut as a cytokine-generating organ in rats subjected to hemorrhagic shock. Shock 1994;1:141145 .
12 Gordillo GM, Sen CK: Revisiting the essential role of oxygen in wound healing. Am J Surg 2003;186:259-263.

13 Tandara AA, Mustoe TA: Oxygen in wound healing - more than a nutrient. World J Surg 2004;28:294-300.

14 Braz JR, do Nascimento P Jr, Paiva Filho O, Braz LG, Vane LA, Vianna PT, Rodrigues GR Jr: The early systemic and gastrointestinal oxygenation effects of hemorrhagic shock resuscitation with hypertonic saline and hypertonic saline 6\% dextran-70: a comparative study in dogs. Anesth Analg 2004;99: 536-546.

15 Paes-da-Silva F, Gonzalez AP, Tibiriçá E: Effects of fluid resuscitation on mesenteric microvascular blood flow and lymphatic activity after severe hemorrhagic shock in rats. Shock 2003; 19:55-60.

16 Knotzer H, Pajk W, Maier S, Dünser MW, Ulmer H, Schwarz B, Salak N, Hasibeder WR: Comparison of lactated Ringer's, gelatine and blood resuscitation on intestinal oxygen supply and mucosal tissue oxygen tension in haemorrhagic shock. Br J Anaesth 2006;97:509-516. 
17 Mazzoni MC, Borgström P, Arfors KE, Intaglietta M: Dynamic fluid redistribution in hyperosmotic resuscitation of hypovolemic hemorrhage. Am J Physiol 1988;255:629637.

18 Chiara O, Pelosi P, Brazzi L, Bottino N, Taccone P, Cimbanassi S, Segala M, Gattinoni L, Scalea T: Resuscitation from hemorrhagic shock: experimental model comparing normal saline, dextran, and hypertonic saline solutions. Crit Care Med 2003;31:19151922.

19 Scalia S, Burton H, Van Wylen D, Steinberg S, Hoffman A, Roche F, Flint L: Persistent arteriolar constriction in microcirculation of the terminal ileum following moderate hemorrhagic hypovolemia and volume restoration. J Trauma 1990;30:713-718.
20 Vajda K, Szabó A, Boros M: Heterogeneous microcirculation in the rat small intestine during hemorrhagic shock: quantification of the effects of hypertonic-hyperoncotic resuscitation. Eur Surg Res 2004;36:338-344.

21 Nascimento P Jr, de Paiva Filho O, de Carvalho LR, Braz JR: Early hemodynamic and renal effects of hemorrhagic shock resuscitation with lactated Ringer's solution, hydroxyethyl starch, and hypertonic saline with or without $6 \%$ dextran-70. J Surg Res 2006;136:98-105.

22 Bahrami S, Zimmermann K, Szelényi Z, Hamar J, Scheiflinger F, Redl H, Junger WG: Small-volume fluid resuscitation with hypertonic saline prevents inflammation but not mortality in a rat model of hemorrhagic shock. Shock 2006;25:283-289.

23 Buchmiller-Crair TL, Kim CS, Won NH, Chopourian HL, Shaw KS, Fonkalsrud EW: Effect of acute anemia on the healing of intestinal anastomoses in the rabbit. J Trauma 2001;51:363-368.
24 Tadros T, Wobbes T, Hendriks T: Blood transfusion impairs the healing of experimental intestinal anastomoses. Ann Surg 1992;215:276-281.

25 Attard JA, Raval MJ, Martin GR, Kolb J, Afrouzian M, Buie WD, Sigalet DL: The effects of systemic hypoxia on colon anastomotic healing: an animal model. Dis Colon Rectum 2005;48:1460-1470.

26 Yagci G, Ozturk E, Ozgurtas T, Gorgulu S, Kutlu OC, Topal T, Cetiner S, Tufan T: Preoperative and postoperative administration of hyperbaric oxygen improves biochemical and mechanical parameters on ischemic and normal colonic anastomoses. J Invest Surg 2006;19:237-244.

27 Eroglu E, Eroglu F, Yavuz L, Agalar C, Agalar F: The effect of colloidal fluid replacement on wound healing in an experimental sublethal hemorrhagic shock model. Eur J Emerg Med 2005;12:282-284. 